\title{
An Echo-friendly and Cost Effective Building for Future Smart Cities ${ }^{+}$
}

\author{
Mohammad Monirujjaman Khan ${ }^{1}$ \\ 1 Department of Electrical and Computer Engineering, North South University, Dhaka-1229, Bangladesh ; \\ * Correspondence: monirujjaman.khan@northsouth.edu; Tel.: +8801779006296 \\ + Presented at the 1st International Electronic Conference on Applied Sciences, \\ 10-30 November 2020; Available online: https://ecsa-6.sciforum.net/
}

Published: 10 November 2020

\begin{abstract}
This paper presents development and delivery of innovative and sustainable building solutions. The solution proposed here will minimize the negative impact of residential sector construction on the environment reduce the energy and resource consumption and increase the over-all sustainability of future smart cities using solar roof tiles, rotating solar panel and power wall. We are going to make a house with the combination of solar roof tiles, rotating solar panel, power wall and latest technologies to make a sustainable cheaper house for the future smart cities.
\end{abstract}

Keywords: Solar Roof Tiles; Rotating Solar Panels; Power wall; Sustainability; Cheaper; Smart City

\section{Introduction}

With rapid urbanization need for better and more comfortable homes are increasing. But as a result of this rapid urbanization, harm is done to the environment. Green house gases are produced from making of raw materials and energy generation for the house which has numerous negative environmental impacts. Lot of energy and resource is consumed and wasted by an average household making it expensive. The house is less sustainable on its own as it can't survive without power from the grid. Gases produce from the fossil fuel powered plants are- Carbon dioxide (CO2), Sulfur oxides, Nitrogen oxides, Mercury. Because of this rapid urbanization the level of CO2 gas in the atmosphere is rising rapidly. Coal burning produces huge amount of CO2.Geothermal, Hydropower and Nuclear systems produce small amount of CO2. Deforestation for power plants will increase $\mathrm{CO} 2$. Methane has heat trapping capacity of $\mathrm{CO} 2$. A power plant that captures methane and increase global warming is also harming the environment. Climate emergency is the greatest driver behind the making of sustainable smart cities. With the arrival of the 21st century's third decade, there are multiple green goals that cities need to achieve. Smart cities around the world are focusing on switching to the use of renewable energy in multiple manners. With that, the efforts are also being seen in improving energy efficiency and cutting the CO2 emissions [1]. On 1st July 2020, Sydney's operations from streetlights, pools, depots, to buildings started to run on $100 \%$ renewable energy. CO2 emissions will reduce by nearly 20,000 tonnes per year. This is equal to the power consumption of over 6,000 households. [2]. According to the study of the United Nations (UN) Environment Programme, buildings at a global level utilize about $40 \%$ of energy, $25 \%$ of water, $40 \%$ of resources, and emit about $33 \%$ of GHG emissions; residential and commercial buildings use about $60 \%$ of the world's electricity [3]. The tendencies of building design and construction have historically changed in a way that is similar to the development path of a smart city: from energy efficient to sustainable, to green, to intelligent, and finally to smart [4]. The main goal of this paper is to develop and deliver innovative and sustainable building solutions that will minimize the negative impact of residential sector construction on the environment reduce the energy and resource 
consumption and increase the over-all sustainability of future smart cities. In order to do these we need to improve the sustainability of communities by developing innovative building solutions. Remove negative impacts of the house on the environment. Make the house more comfortable while cutting down energy waste. The US Energy Information Administration recently reported that the world will consume over 21,000 TWh of electricity overall in 2020. And over the next three decades, global consumption will probably increase by $50 \%$ [5]. This proposed cost effective building will reduce consumption of energy and resource made by the house. Our vision is to become $100 \%$ off grid. That means we won't take any electricity supply from the grid. Most houses at present are built using conventional techniques with brick, cement and rods. Not only these houses are risky to be in when an earthquake strikes, but are also expensive to built, wastes lot of energy and causes harm to the environment. On the other hand it has less implementation of software and technology to save energy that makes life more comfortable and safe. Addressing all these problems we are going to make a house with the combination of solar tiles, rotating solar panel, power wall and latest technologies to make a sustainable cheaper house for the future smart cities. Development and delivery of innovative and sustainable building solutions that will minimize the negative impact of residential sector construction on the environment reduce the energy and resource consumption and increase the over-all sustainability of future smart cities using solar roof tiles, rotating solar panel and power wall.

Modern power systems are facing increased challenges such as increased energy demand, environmental concerns, etc., which cannot be met by the utility grid alone. Building micro grid networks can meet these challenges to some extent, which employs renewable energy sources which are eco-friendly to reduce the environmental concerns. Smart and energy-efficient buildings, which is a recent trend in building industry minimizes energy consumption. The Energy Management System (EMS) in a building is designed to improve environment within the building to ensure customers' comfort. Smart Homes (SH) can use a variety of renewable energy sources, including photovoltaic (PV) arrays, micro-wind turbine, Heat Pumps (HPs), and Plug-in Electric Vehicle (PEV) as an energy storage. The tendencies of building design and construction have historically changed in a way that is similar to the development path of a smart city: from energy efficient to sustainable, to green, to intelligent, and finally to smart.

Some $12 \%$ of the UK's carbon emissions come from domestic buildings and the government has declared that by 2020, all homes must be zero carbon. The popularity of eco-properties is growing around the globe. There's no denying that eco homes have grown in popularity over the years, and this shows no signs of slowing down. Environmentally-friendly and money-saving are a winning combination; and it turns out that eco builds aren't as expensive as you'd think.

\section{Method and Material}

\subsection{Ease of Use}

The proposed innovative and sustainable building solutions would help to create a greener and safer environment which will be pollution free. The environmental impacts from energy generation for the house can be reduced using solar tiles, which is cheaper than solar panels and rotating solar panels. This will help the house survive without power from the grid. Software and sensors can be used to detect and stop wastage, while making the house more comfortable to live in and cutting down energy usage. The environmental impacts from making of raw materials for the house, for example brick, can be reduced constructing the house with glass, solar windows and steel/wood frames or pillars. It will also make construction cheaper. The power walls will also provide energy for the house.

\subsection{Syatem Working Procedures}

Power supply solution for the house will be:

a) Solar roof tiles. 
b) Rotating solar panel.

c) Power wall.

\subsubsection{Solar Roof Tiles}

Solar roof tiles provide an alternative to conventional solar panels. Figure 1 presents Solar Roof Tiles. Instead of being installed on existing roofs with racking systems, solar tiles are part of the roof itself [6]. Solar roof tiles can be used to provide energy for the house instead of energy from the main grid. This will reduce the consumption of energy from fossil fuels which have harmful environmental effect. Solar tiles are basically a better substitute of solar panels. They produce approximately same power as a solar panel but provide good insulation and is cheaper to install. On the other hand they give the house a better look, and hence are more attractive product to the resident of the house. Smart cities are used to installing solar panels on the roofs of buildings [7]. With all the extraordinary ingenious developments attained over the previous years in solar innovation, solar roof is now more economical than ever. The Solar roof is made up of roof tiles itself with integrated systems of solar cells built within the tiles. Solar tiles operate identically to the photovoltaic panels that are already widely used in construction. The primary difference between them lies in their assembly: whereas photovoltaic panels are attached to an existing roof, solar tiles are part of the roof's construction from the start, taking the place of regular tiling.

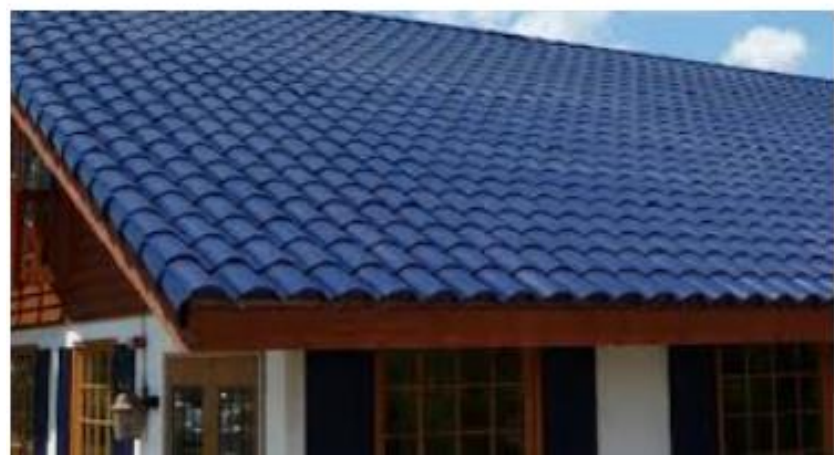

Figure 1. Solar Roof Tiles.

The tiles are formed by photovoltaic cells that, when they receive sunlight, create an electric field capable of providing electrical energy for use inside the building. Each tile is connected by cables to the power distribution board. For the effective operation of the tiles, it is necessary to install an inverter that converts the energy captured by each tile into electricity. The quantity of energy collected through solar energy is directly related to the amount of sunlight to which the tiles are exposed, which is obviously related to the climate and the location. Sunny days, of course, are more energy-efficient than cloudy days. Solar tiles are an excellent source of renewable energy for regions with high solar incidence.

\subsubsection{Rotating Solar Panel}

Sun Tracking System for Solar panel is design to tracking the Sun at day time for utilizing its solar energy properly for solar panel. This system orients the Solar Panel towards the sun, so that it can utilize with higher accuracy. The system track the Sun by use of sensors and rotate the solar panel by means of stepper motor. A solar tracking system maximizes your solar system's electricity production by moving your panels to follow the sun throughout the day, which optimizes the angle at which your panels receive solar radiation [8]. Figure 2 shows the Solar tracking system. Solar trackers help maximize solar production by following the sun throughout the day. A solar tracking system maximizes your solar system's electricity production by moving your panels to follow the sun throughout the day, which optimizes the angle at which your panels receive solar radiation. Solar trackers are typically used for ground-mounted solar panels and large, free-standing solar 
installations like solar trees. When solar panels are exposed to sunlight, the angle at which the sun's rays meet the surface of the solar panel (known as the "angle of incidence") determines how well the panel can convert the incoming light into electricity. The narrower the angle of incidence, the more energy a photovoltaic panel can produce. Solar trackers help to minimize this angle by working to orient panels so that light strikes them perpendicular to their surface. There are two types of solar tracking systems: single-axis and dual-axis.

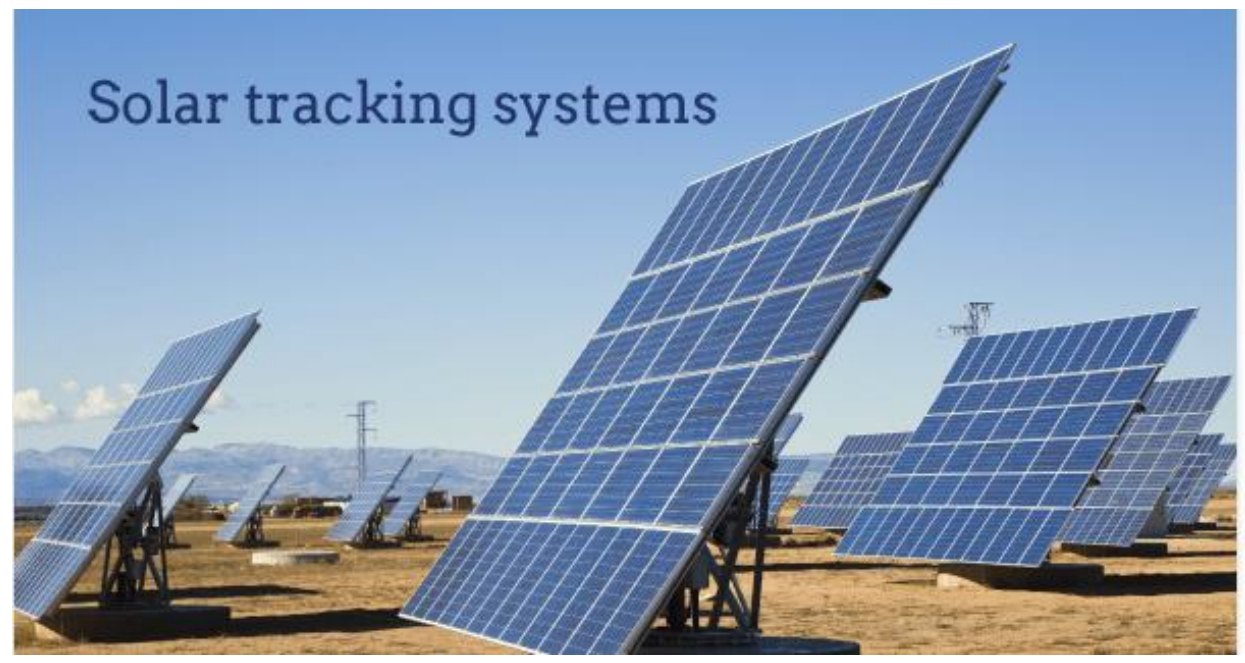

Figure 2. Solar tracking system.

A single-axis tracker moves your panels on one axis of movement, usually aligned with north and south. A dual-axis tracker allows your panels to move on two axes, aligned both north-south and an east-west. This type of system is designed to maximize your solar energy collection throughout the year. The biggest benefit of a solar tracking system is that it offers a boost in electricity production. Generally, a solar panel system with a single-axis solar tracker installed sees a performance gain of 25 to 35 percent. A dual-axis tracker bumps performance up by another five to 10 percent.

\subsubsection{Power Wall}

A common argument against solar power is that it does not produce enough energy for the whole house to be sustainable on its own from day to night. But with addition of solar tiles and rotating panels together to efficiently consume solar power, good amount of electricity can be produced throughout the day, especially during the peak hours of noon. The extra energy produced during the day can be stored in numerous batteries so that it can be use at night. With the advancement of technology a batteries now can store more electricity and is cheaper to buy, for example, Tesla's power wall 2. [9]. Figure 3 presents Tesla power wall. Powerwall is a battery that stores energy, detects outages and automatically becomes your home's energy source when the grid goes down. Unlike gasoline generators, Powerwall keeps your lights on and phones charged without upkeep, fuel or noise. Pair with solar and recharge with sunlight to keep your appliances running for days. The Powerwall is rechargeable lithium-ion battery stationary energy storage product. The Powerwall is intended to be used for home energy storage and stores electricity for solar self-consumption, time of use load shifting, backup power, and off-the-grid use. Powerwall is charged by solar during the day, when solar panels are producing more electricity than the home is consuming. Powerwall then stores that energy until the home needs it, such as when solar is no longer producing at night, or when the utility grid is offline during a power outage.

- Cost of Battery: Battery costs between $\$ 400-\$ 450$ per Kilowatt of power generated.

So we need $10 \mathrm{Kw}=\$ 10 * \$ 425=\$ 4250$. Total cost of Panels \& Battery is calculated as= 


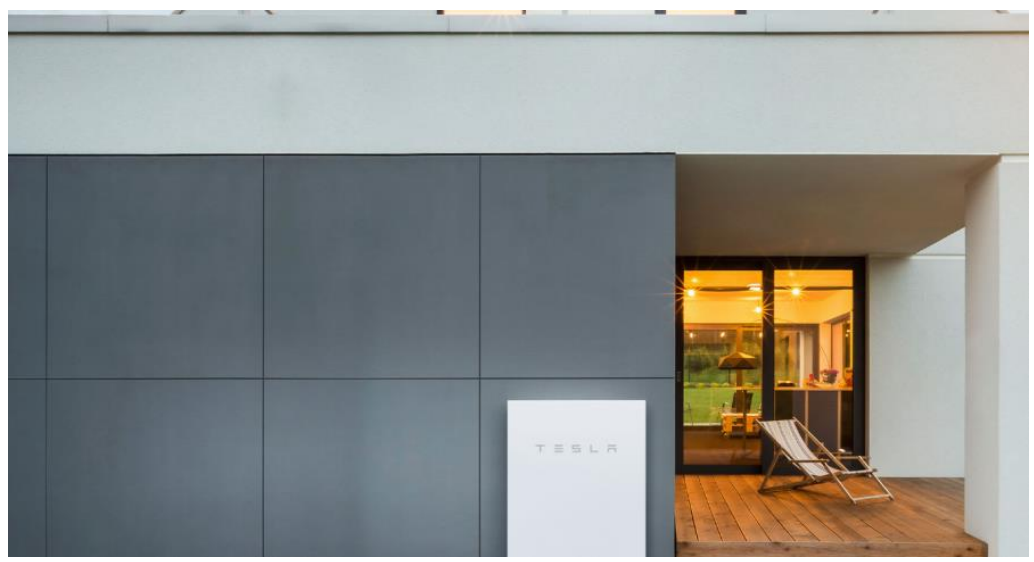

Figure 3. Tesla Power wall.

\subsubsection{Reducing Energy Wastage}

Electrically energy wastage can be reduced using automatic room light controller. More efficient LEDs can be used which require less electrical energy. Temperature of the room can be automatically controlled using sensors. Adjusted during the day brightness of the room can be to save more energy. Implementation of the process will be very cheap because price of microcontrollers and sensor is very low. Automatic Room Lighting System is a microcontroller based system that automatically turn on or off the lights in a room. We often forget to switch off lights or fans when we leave a room. By using this system, we can intentionally forget about the lights as the system will automatically take care of them. The digital World we are living in allows us to use different technologies to automatically perform certain tasks. Such automation is very useful in certain areas like energy consumption, reducing human efforts, improving standard of living etc.

\section{Results and Analysis}

\subsection{Construction}

Primary materials for house construction can be glass and steel. For resident who prefers even cheaper raw material, it can be glass and wood. The main frame and pillars can be constructed with steel/wood while the walls can be of glass. This replacement of bricks and cement house with glass is way of cutting down brick usage, hence reducing green house gas emission from brick fields to zero, on the other hand making the architectural design of the house more appealing to the resident.

\subsubsection{Cost of Construction}

Table 1. Cost of construction.

\begin{tabular}{ccc}
\hline Location & Size & Price \\
\hline For 1st floor & $102 \mathrm{~m}^{\wedge} 2$ & $\$ 316.2$ \\
\hline For 2nd floor & $102 \mathrm{~m}^{\wedge} 2$ & $\$ 316.2$ \\
\hline For garage & $21 \mathrm{~m}^{\wedge} 2$ & $\$ 65.1$ \\
\hline Total Cost & & $\$ 697.5$ \\
\hline
\end{tabular}

\subsubsection{Design and Structure}

In Figures 5, 5 and 6 innovative and sustainable home design with inside view are presented. 


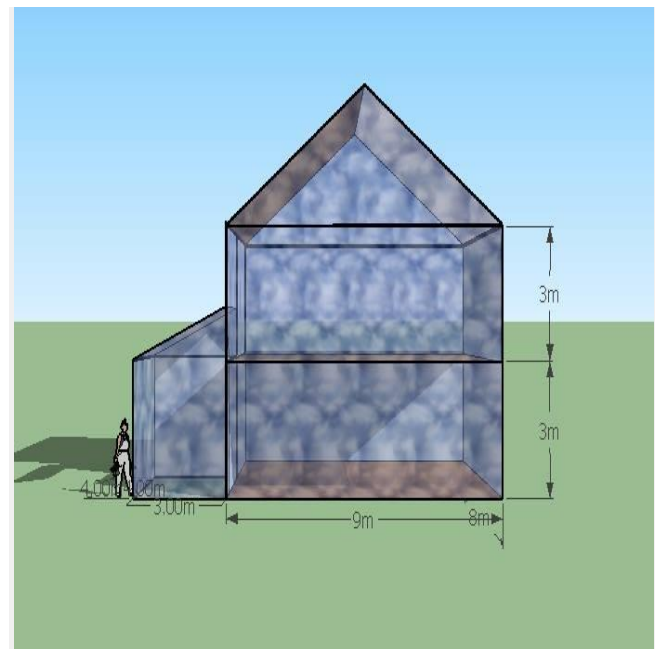

Figure 4. Home design.

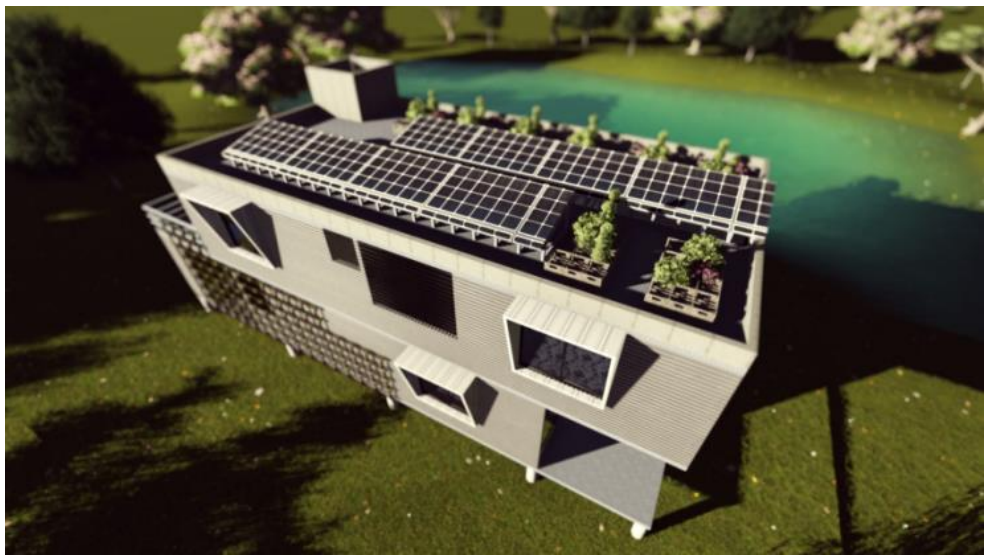

Figure 5. Home design

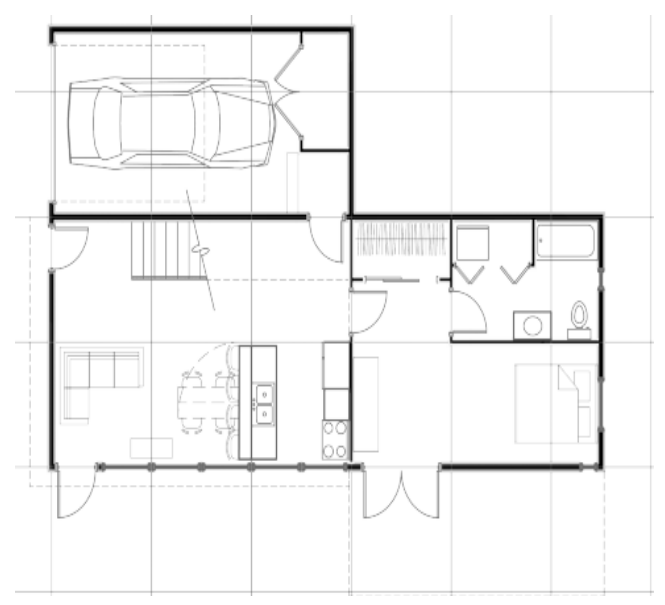

Figure 6. Home design inside view.

\subsubsection{Cost Calculation of an Average House}

Approximate area of a floor $=8 \mathrm{~m}^{*} 9 \mathrm{~m}=72 \mathrm{~m}^{\wedge} 2$

Total floor space $=(72 * 2)+12=156 \mathrm{~m}^{\wedge} 2$

Linear wall total $=2 *(8+9)=34 \mathrm{~m}$

$156^{*} 75$ bricks $=11700$ bricks 
Bricks $=11700$ pieces $=93600$ BDTK (if 8 BDTK per brick)

Steel $-4.25 \mathrm{kgs}$ per sft of built up area $=1680 * 4.25=7140 \mathrm{~kg}=527431$ BDTK (if $67000 \mathrm{BDTK} / \mathrm{ton}$ )

Cement -0.4 bags per sft of built up area $=1680^{*} .4=672$ bags=268800 BDTK (if 400 BDTK/Bag)

Fine Sand (Concrete)- $0.9 \mathrm{cft}$ per sft of built up area $=1680^{*} 0.9=1512 \mathrm{cft}=45360$ BDTK (if 30 $\mathrm{BDTK} / \mathrm{cft})$

Aggregate $-1.3 \mathrm{cft}$ per sft of built-up area $=1680^{*} 1.3=2184 \mathrm{cft}=283920 \mathrm{BDTK}$ (if $130 \mathrm{BDTK} / \mathrm{cft}$ )

Fine Sand (Plaster) - $0.56 \mathrm{cft}$ per sft of built up area $=1680^{*} .56=940.8 \mathrm{cft}=32928 \mathrm{BDTK}$ (if 35BDTK/cft)

Table 2. Cost of calculation of an average house .

\begin{tabular}{cc}
\hline Raw Materials & Cost \\
\hline Bricks & 93600 BDT \\
\hline Steel & 527431 BDT \\
\hline Cement & 268800 BDT \\
\hline Fine & 45360 BDT \\
\hline Aggregate & 283920 BDT \\
\hline Fine Sand(Plaster) & 32928 BDT \\
\hline Total Cost & $\mathbf{1 2 5 2 0 0 0 ~ B D T}$ \\
\hline
\end{tabular}

3.1.4. Total Cost Calculation

Total cost of Panels \& Battery and construction

$=\$ 4250+\$ 3500+1686.7=\$ 9436.7$

\subsection{How this house is better than ordinary house?}

- The solar roof tile gives more insulation.

- Less harm is to environment.

- Looks better hence more desirable to the residents.

- Lowers cost for using cheaper materials.

- It is sustainable and requires little or no power from the grid.

- Uses more efficient ways of energy generation.

- No need to pay electric bills.

- Lighter and safer. Would provide better protection during earthquakes.

- Software used in the house reduces human effort and provides more comfort and at the same time reduces energy wastage.

Buildings represent a very polluting sector: between the construction of houses and tertiary buildings and their occupation and use (for heating, lighting, water...), they represent a considerable consumption of resources and energy. Therefore, it's important to put in place strategies to reduce the ecological impact of buildings and make them more eco-friendly. Specifically, green buildings usually have good insulation (allowing better temperature management) and efficient lighting and heating systems. They often also have renewable energy generators (photovoltaic panels) and water heating panels. These green buildings can also be made of eco-friendly building materials, reducing VOC (volatile organic compounds) emissions. Efficient plumbing fixtures are all common. So using systems that combine better insulation, a smarter and more economical electrical system or lighting specifically designed to optimize light, sustainable buildings can reduce expenses. In the end, green buildings are therefore both environmentally sustainable and economically profitable. Now a days the increase in the cost of construction materials is a great issue that we face in our society, that is due to the scarcity of natural resources. While constructing a building we must aware about the 
safety of the environment by promoting more eco-friendly construction in our world. Through this we can maintain sustainability. We humans all are highly depend on non renewable energy resources for various constructions, so natural resources become vanished and cost and demand of materials increases as a result. There should be an end in the increase in the cost of construction field and keep sustainability. A shelter is a basic architectural structure or building that provides protection from the local environment. Having a place of shelter, of safety and of retreat is commonly considered a fundamental psychological human need, the foundation from which to develop higher human motivations. Insulation is one of the most important things that you need to consider while building a green home. Heating and cooling account for $50 \%$ of your home's energy consumption. Air leaks such as around windows, doors and ductwork are responsible for building heat loss. The use of Green Insulation has proven to be a sustainable construction technology as it eliminates the need for high-end finishes made from non-renewable materials. Solar energy is a clean and renewable source of energy. Solar panels are an emerging and hot technology for people who want to utilize the natural power all around us, the sun. Solar panels may be expensive at first, but the long-term savings you can put into your pocket is a stunning example of the benefits of turning your life from black to green. Both LED and CFL cost more upfront but use less energy and last longer than traditional incandescent bulbs. Since they offer significant cost savings in the long run, they can be ideal for your new green home.

The material used on your roof can make a dramatic difference in your home's energy efficiency. You may want to consider a product that reflects the sun's energy away from the roof, cools faster at night and holds less heat for less time in order to help reduce energy costs and usage related to heat. Slate, terra cotta, white tiles, special membranes, and metal roofing are a few of the roofing products available with varying degrees of green benefits. Electronic Smart Glass also constitutes one of the technologies in sustainable construction. This new technology works particularly in summer periods to shut out the harsh heat of solar radiation. The smart glass uses tiny electric signals to slightly charge the windows to change the amount of solar radiation it reflects. Sustainable construction technologies mean mechanisms that lessen energy consumption.

\section{Conclusion}

Development and delivery of innovative and sustainable building solutions are shown and discussed. By constructing this innovative house we target to achieve reduction in the impact of residential sector construction on the environment and an increase in the social, environmental and economic sustainability. There is great benefit of this building for the development of sustainable smart cities. It is a house with the combination of solar tiles, rotating solar panel, power wall and latest technologies to make a sustainable cheaper house for the future smart cities. Green building -or sustainable building- is the practice of increasing the efficiency with which buildings and their sites use energy, water, and materials, and of reducing impacts on human health and the environment for the entire life-cycle of a building [10].

Funding: This research was self funded. No external fund has been received.

Acknowledgments: Author would like to thank Department of Electrical and Computer Engineering Department North South university.

Conflicts of Interest: The authors declare no conflict of interest.

\section{References}

1. Word's First Initiatives Saving Energy in Smart Cities. Available online: https://www.smartcity.press/smart-city-energy-saving-initiatives/(accessed on 7th May 2020)

2. Sydney Using $100 \%$ Renewable Electricity. Available online: https://www.smartcity.press/smart-city-energy-saving-initiatives/(accessed on 7th May 2020)

3. UNEP. Energy Efficiency for Buildings; United Nations Environment Programme, United Nations: New York, NY, USA, 2009. 
4. Buckman, A.H.; Mayfield, M.; Beck, S.B.M. What is a Smart Building? Smart Sustain. Built Environ. 2014, 3, 92-109.

5. Novel Ways of Generating Renewable Energy. Available online: https://www.smartcity.press/renewable-energy-sources/ (accessed on 7th May 2020)

6. Solar Roof Tiles: Advantages and Disadvantages. Available online: https://www.ny-engineers.com/blog/solar-roof-tiles-advantages-and-disadvantages\#: :text=Solar\%20roof \%20tiles\%20provide\%20an,part\%20of\%20the\%20roof\%20itself.\&text=Solar\%20roof $\% 20$ tiles $\% 20$ are $\% 20$ als o\%20known\%20as\%20solar\%20shingles. (accessed on 5th May 2020)

7. Creating Energy-Harvesting Surfaces. Available online: https://www.smartcity.press/smart-city-energy-saving-initiatives/(accessed on 7th May 2020)

8. Solar Tracking System, Available online: https://news.energysage.com/solar-trackers-everything-need-know/\#: :text=A\%20solar\%20tracking\%20sy stem\%20maximizes,your\%20panels\%20receive\%20solar\%20radiation. (accessed on 5th May 2020)

9. Power Wall. Available online: https://www.tesla.com/powerwall (accessed on 5th May 2020)

10. Green Buildings and Its Benefits in Smart Cities. Available online: https://www.ierek.com/news/index.php/2017/08/01/smart-cities/(accessed on 5th May 2020)

(C) 2020 by the authors; licensee MDPI, Basel, Switzerland. This article is an open access article distributed under the terms and conditions of the Creative Commons Attribution (CC-BY) license (http://creativecommons.org/licenses/by/4.0/). 